\title{
Novel synthetic coumarins that targets NF-kB in Hepatocellular carcinoma
}

\author{
Mahabaleshwaraiah Neelgundmath ${ }^{\mathrm{a}, \mathrm{b}, \dagger}$, Koragere Rajashekar Dinesh ${ }^{\mathrm{c}, \dagger}$, \\ Chakrabhavi Dhananjaya Mohan ${ }^{\mathrm{d}, \dagger}$, Feng $\mathrm{Li}^{\mathrm{e}}{ }$, Xiaoyun Dai ${ }^{\mathrm{e}}$, Kodappully Sivaraman Siveen ${ }^{\mathrm{e}}$, \\ Shardul Paricharak f,g, Daniel J. Mason ${ }^{f}$, Julian E. Fuchs ${ }^{\mathrm{f}}$, Gautam Sethi ${ }^{\mathrm{e}}$, Andreas Bender ${ }^{\mathrm{f}}$, \\ Kanchugarakoppal S. Rangappa ${ }^{\mathrm{d}}$, Obelannavar Kotresh ${ }^{\mathrm{b}, *}$, Basappa ${ }^{\mathrm{c}, *}$ \\ ${ }^{a}$ Department of Chemistry, P.C. Jabin Science College, Hubli, India \\ ${ }^{\mathrm{b}}$ Department of Chemistry, Karnataka Science College, Dharwad, India \\ ${ }^{c}$ Laboratory of Chemical Biology, Department of Chemistry, Bangalore University, Central College Campus, Palace Road, Bangalore 560001, India \\ ${ }^{\mathrm{d}}$ Department of Studies in Chemistry, Manasagangotri, University of Mysore, Mysore 570005, India \\ e Department of Pharmacology, Yong Loo Lin School of Medicine, National University of Singapore, 117597 Singapore, Singapore \\ ${ }^{\mathrm{f}}$ Centre for Molecular Science Informatics, Department of Chemistry, University of Cambridge, Lensfield Road, CB2 1EW Cambridge, United Kingdom \\ ${ }^{\mathrm{g}}$ Division of Medicinal Chemistry, Leiden Academic Centre for Drug Research, Leiden University, PO Box 9502, 2300 RA Leiden, The Netherlands
}

\section{A R T I C L E I N F O}

\section{Article history:}

Received 31 August 2014

Revised 27 November 2014

Accepted 19 December 2014

Available online 30 December 2014

\section{Keywords:}

Hepatocellular carcinoma

Coumarin

NF- $\kappa B$

Bioinformatics

Inflammation

\begin{abstract}
A B S T R A C T
Hepatocellular carcinoma (HCC) is the fifth most common malignant tumor worldwide, and is the third most common cause of cancer related death. Constitutive activation of NF- $\kappa \mathrm{B}$ is the underlying mechanism behind tumorigenesis and this protein regulates the expression of genes involved in proliferation, survival, drug resistance, angiogenesis and metastasis. The design of inhibitors which suppress NF- $\mathrm{KB}$ activation is therefore of great therapeutic importance in the treatment of HCC. In this study, we investigated the effect of newly synthesized coumarin derivatives against HCC cells, and identified (7-Carbethoxyamino-2-oxo-2H-chromen-4-yl)methylpyrrolidine- 1 carbodithioate (CPP) as lead compound. Further, we evaluated the effect of CPP on the DNA binding ability of NF- $\mathrm{KB}$, CXCL12-induced cell migration and invasion, and the regulated gene products in HCC cells. We found that CPP induced cytotoxicity in three $\mathrm{HCC}$ cells in a time and dose dependent manner, and suppressed the DNA binding ability of NF- $\mathrm{KB}$. CPP significantly decreased the CXCL12-induced cell migration and invasion. More evidently, CPP inhibits the expression of NF- $\kappa$ B targeted genes such as cyclin D1, Bcl-2, survivin, MMP12 and C-Myc. Furthermore, the molecular docking analysis suggested that CPP interacts with the p50 binding domain of the p65 subunit, scoring best among the 26 docked coumarin derivatives of this study. Thus, we are reporting CPP as a potent inhibitor of the pro-inflammatory pathway in Hepatocellular carcinoma.
\end{abstract}

(c) 2014 Elsevier Ltd. All rights reserved.
Hepatocellular carcinoma (HCC) is the most common form of liver cancer, and is the third most common cause of cancer related mortality. ${ }^{1}$ Obesity, hepatitis B or hepatitis $C$ virus infection, consumption of aflatoxin $\mathrm{B} 1$, and alcoholic hepatitis are the major risk factors of HCC. ${ }^{2}$ The majority of patients with HCC are diagnosed at a late stage of the disease, with therapy limited to only liver transplantation and surgical liver sectioning. Early detection of HCC may contribute to the strengthening of prognosis. ${ }^{3,4}$ Nuclear factor

Abbreviation: CPP, (7-Carbethoxyamino-2-oxo-2H-chromen-4-yl)methylpyrrolidine-1 carbodithioate.

* Corresponding authors. Tel.: +91 9686449876 (Basappa).

E-mail address: salundibasappa@gmail.com (Basappa).

$\dagger$ These authors contributed equally. kappa $\mathrm{B}(\mathrm{NF}-\kappa \mathrm{B})$ is an inducible transcription factor present ubiquitously in the cytoplasm of almost all mammalian cells, and was identified by Baltimore and colleagues in $1986 .{ }^{5}$ In an unstimulated cell, NF- $\kappa \mathrm{B}$ is associated with I $\kappa \mathrm{B}$ (inhibitory $\kappa \mathrm{B}$ ), and resides in the cytoplasm. ${ }^{6}$ Different ligands acting upon the receptor result in a cascade of upstream kinases, finally leading to phosphorylation and ubiquitylation of $\mathrm{I} \kappa \mathrm{B}$, which is targeted for degradation. NF$\kappa \mathrm{B}$ translocates into nucleus and regulates transcription of the genes involved in inflammation. ${ }^{7} \mathrm{NF}-\kappa \mathrm{B}$ is referred to as a double-edged sword by researchers because of its critical role in proper functioning of the immune system, and the possibility that oncogenesis may arise from the slightest change in regulation. ${ }^{8}$ Several anti-apoptotic, angiogenic, inflammatory, metastasis-related, and 


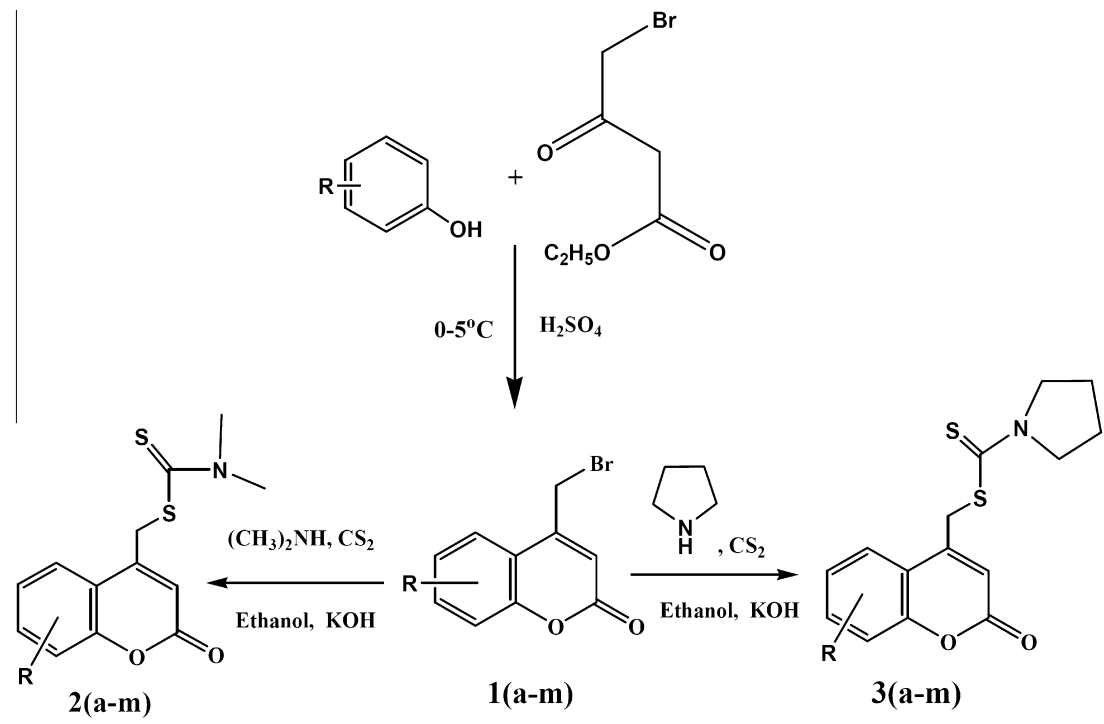

$\mathrm{R}=6-\mathrm{CH}_{3}, 7-\mathrm{CH}_{3}, 5,6-\mathrm{Benzo}, 7,8-\mathrm{Benzo}, 6-\mathrm{OCH}_{3}, 7-\mathrm{OCH}_{3}, 6-\mathrm{Cl}, 7-\mathrm{Cl}, 6-\mathrm{F}, 7-\mathrm{F}, 5,7-\mathrm{Dimethyl}, 7-$

Carbmethoxylamime, 7-Carbethoxylamine

Figure 1. Synthesis of coumarin-based small molecules libraries.

e

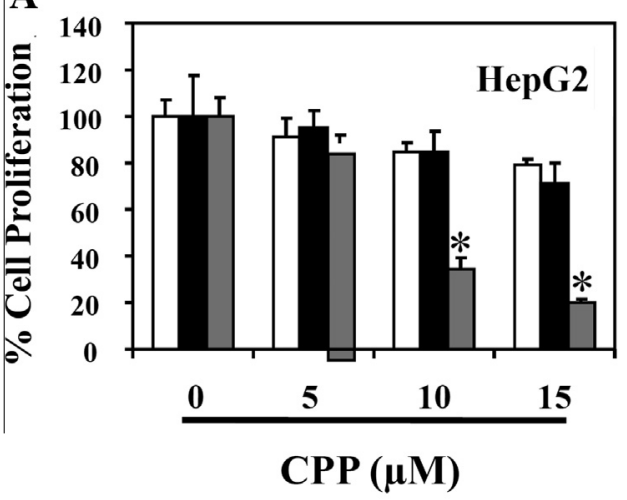

B

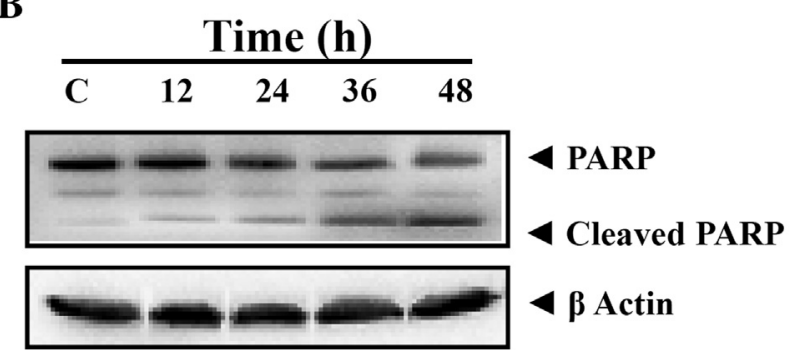

Figure 2. (A) HepG2 cells $\left(5 \times 10^{3} / \mathrm{mL}\right)$ were plated in triplicate, treated with indicated concentrations of CPP, and then subjected to MTT assay after 24, 48 and $72 \mathrm{~h}$ to analyze proliferation of cells. Standard deviations between the triplicates are indicated. *Indicates $p$ value $<0.05$. (B) CPP potentiates PARP cleavage. HepG2 cells $\left(2 \times 10^{6} / \mathrm{mL}\right)$ were treated with CPP for time intervals, after which whole-cell extracts were prepared and $30 \mu \mathrm{g}$ protein of those extracts were resolved on $10 \%$ SDS-PAGE, membrane sliced according to molecular weight and probed against PARP antibodies. The same blots used to detect $\beta$-actin to verify equal protein loading.

proliferative proteins, including cIAP, Bcl-2, c-Myc, MMP 12, and $\mathrm{COX} 2$, are regulated by NF- $\mathrm{KB}$ signaling.,9

Coumarins were originally isolated in early 1820 from tonka beans, and were later used for various domestic purposes. ${ }^{10}$ Since

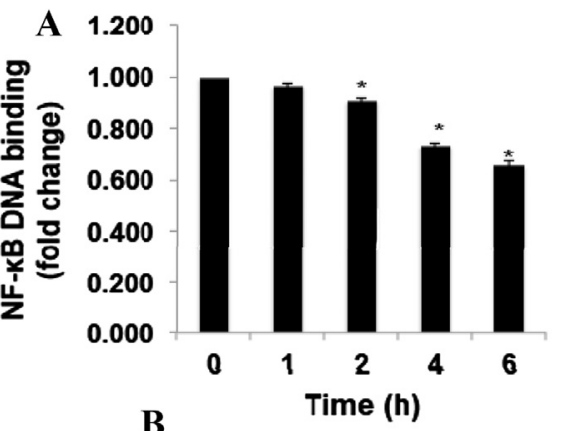

B

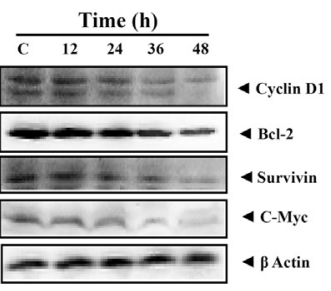

C

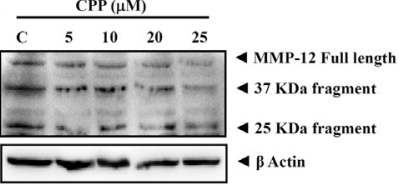

Figure 3. (A) CPP suppresses NF- $\kappa B$ DNA binding ability in HepG2 cells. HepG2 cells were treated with $50 \mu \mathrm{M}$ CPP for indicated time points; nuclear extracts were prepared, and $5 \mu \mathrm{g}$ of the nuclear extract protein was used for ELISA-based DNA binding assay. The results shown are representative of two independent experiments ${ }^{*} P<0.05$. (B) CPP suppresses NF- $\mathrm{BB}$ regulated gene products involved in proliferation, survival and angiogenesis. HepG2 cells $\left(2 \times 10^{6} / \mathrm{mL}\right)$ were treated with $50 \mu \mathrm{M}$ CPP for indicated time intervals, after which whole-cell extracts were prepared and $30 \mu \mathrm{g}$ proteins of those extracts were resolved on 10\% SDS-PAGE, membrane sliced according to molecular weight and probed against cyclin D1, Bcl2 , survivin and C-Myc antibodies. The same blots were stripped and reprobed with $\beta$-actin antibody to verify equal protein loading. The results of cyclin D1, Bcl-2, survivin and C-Myc shown are representative of two independent experiments. (C) CPP induces MMP12 cleavage. HepG2 cells $\left(2 \times 10^{6} / \mathrm{mL}\right)$ were treated with CPP for indicated concentrations, after which whole-cell extracts were prepared and $30 \mu \mathrm{g}$ proteins of those extracts were resolved on 10\% SDS-PAGE, membrane sliced according to molecular weight and probed against MMP12 antibodies. The same blots used to detect $\beta$-actin to verify equal protein loading. 

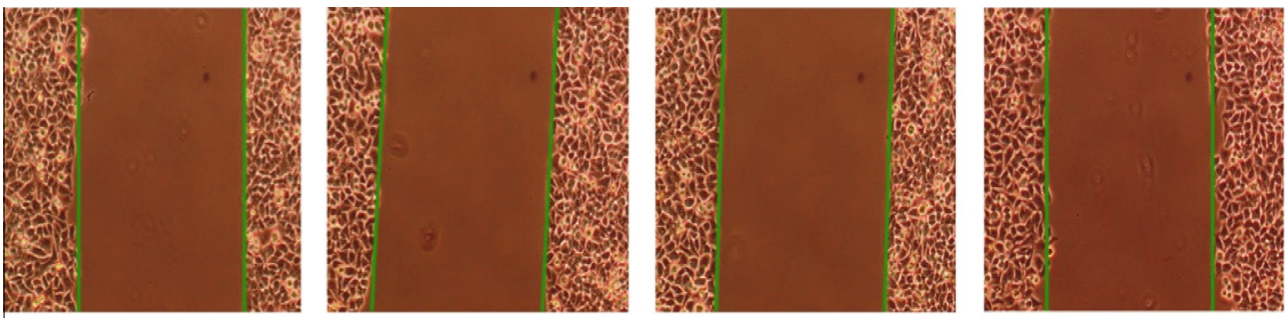

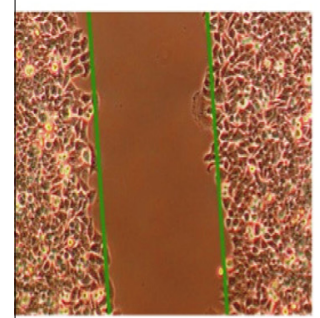

Control

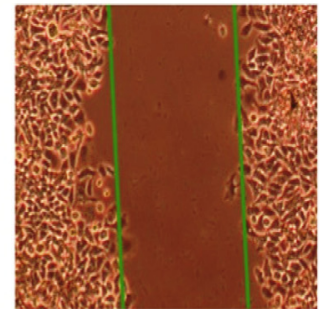

CPP

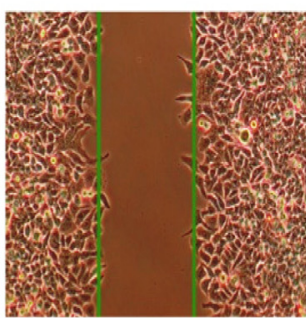

CXCL12

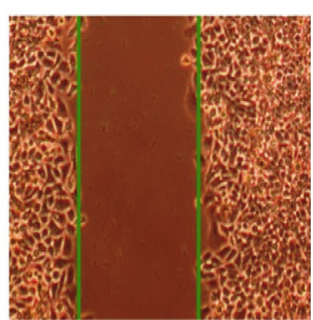

CPP + CXCL12

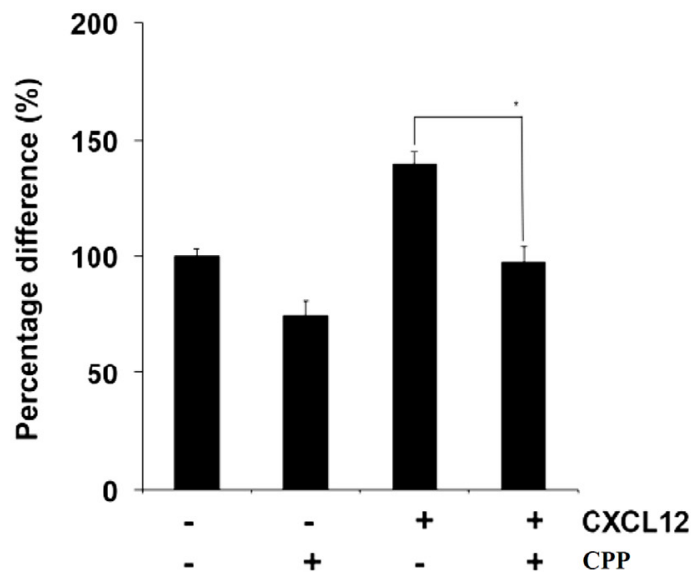

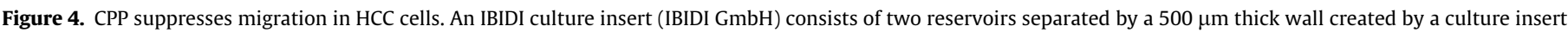

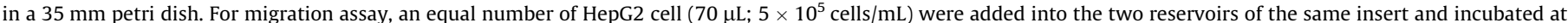

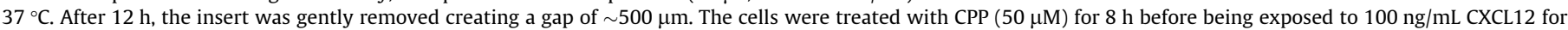

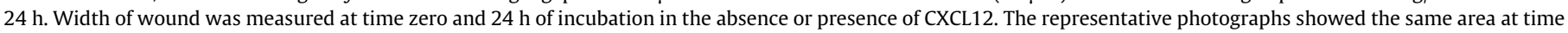
zero and after $24 \mathrm{~h}$ of incubation and columns represent mean distance of migrated cells in the presence or absence of CPP and CXCL12.

their first identification, researchers have discovered an enormous number of coumarin based natural compounds with different pharmacological properties. Fraxetin, esculetin, and daphnetin are some of the coumarin related natural compounds with very good inhibitory activity against cyclooxygenase and lipoxygenase. ${ }^{11}$ Researchers have exploited the anti-tumor, appetite-suppressor, anti-inflammatory and antioxidant activities of many natural and synthetic coumarin based compounds both in vitro and in vivo. ${ }^{12}$ As part of our continued research into identification of new inhibitors against various signaling cascades in cancer and inflammation, herein, we investigated whether coumarins may exert their anticancer effect by disruption of NF- $\kappa B$ signaling. ${ }^{13-19}$ We synthesized a library of coumarin derivatives, and evaluated their effect on Hepatocellular carcinoma cells. We found (7-Carbethoxyamino2-oxo-2H-chromen-4-yl)methylpyrrolidine-1 carbodithioate (CPP) to be a potent cytotoxic molecule, causing significant reduction in $\mathrm{NF}-\kappa \mathrm{B}$ targeted gene products, increasing apoptosis, and suppressing the DNA binding ability of NF- $\kappa \mathrm{B}$.

The synthetic route for coumarin-based small molecule libraries is outlined in Figure 1. 4-Bromoethylacetoacetate is obtained from the bromination of ethyl-acetoacetate, and subsequently treated with various substituted phenols under Pechmann cyclization conditions using concentrated sulfuric acid as the dehydrating agent, ${ }^{20}$ which results in the formation of substituted-4-bromomethylcoumarins $\mathbf{1}(\mathbf{a}-\mathbf{m})$. A one pot reaction of carbon disulfide and dimethylamine/pyrrolidine in ethanol was prepared for compounds $\mathbf{1}(\mathbf{a}-\mathbf{m})$, stirring at room temperature for $24 \mathrm{~h}$, which resulted in the formation of coumarinyldithiocarbamates (Fig. 1). Organic materials were extracted with dichloromethane, before being separated and dried over anhydrous $\mathrm{Na}_{2} \mathrm{SO}_{4}$. The solvent was removed under reduced pressure to obtain the desired products, and the crude product was further purified by flash column chromatography. In some cases, it was necessary to obtain crystallized structures from the mixture of ethanol and chloroform solvents. The structures of all the target compounds were characterized by elemental analysis, GCMS, IR, ${ }^{1} \mathrm{H}$ NMR, and ${ }^{13} \mathrm{C}$ NMR spectrometry.

We investigated cytotoxic effect of a newly synthesized series of compounds on HepG2 cells using an MTT assay as described previously (Supplementary Table 3). ${ }^{21,22}$ CPP was found to be most effective compound among the tested compounds, and MTT assay was used to further investigate whether CPP can inhibit the proliferation of HepG2, PLC/PRF5, and Huh7. Our results showed that CPP inhibits the proliferation of all the three cell lines (data not shown for PLC/PRF5 and Huh7) in both a dose and time dependent manner (Fig. 2A). However CPP did not show high cytotoxic effect 
on LO2 cells up to $72 \mathrm{~h}$ at $50 \mu \mathrm{M}$ indicating that the CPP does not have cytotoxic effect on normal cells.

We also investigated whether suppression of constitutively active NF- $\kappa B$ in HepG2 cells by CPP leads to apoptosis. CPP induced time-dependent cleavage of a $116 \mathrm{kDa}$ Poly ADP-ribose polymerase (PARP) protein into an $85 \mathrm{kDa}$ fragment (Fig. 2B). These results clearly suggest that CPP induces substantial apoptosis in HepG2 cells.

$\mathrm{NF}-\kappa \mathrm{B}$ is a transcription factor that plays an important role in cell proliferation and survival. Therefore, we investigated whether CPP can modulate the DNA binding activity of NF- $\kappa B$ in HCC cells. Analysis of nuclear extracts prepared from HepG2 cells, using an ELISA based TransAM NF- $\kappa$ B assay kit, showed that CPP inhibited the NF- $\kappa B$-DNA binding activities in a time dependent manner (Fig. $3 \mathrm{~A})$. These results suggest that $\mathrm{CPP}$ can suppress the DNA binding ability of NF- $\kappa B$.

$N F-\kappa B$ activation has been shown to regulate the expression of various gene products involved in cell survival, proliferation, angiogenesis and chemoresistance. ${ }^{5,23,24}$ We found that expression of the cell cycle regulator cyclin D1, and the antiapoptotic proteins $\mathrm{Bcl}-2$, survivin, and, C-Myc, and MMP12 which are reported to be regulated by $\mathrm{NF}-\kappa \mathrm{B}$, were modulated by CPP treatment. Their expression decreased across different dose and time intervals (Fig. 3B and C).

We also determined the effect of CPP on HCC cell invasion, a key hallmark of cancer. ${ }^{25,26}$ Using an in vitro migration assay, we found that HepG2 cells migrated faster under the influence of CXCL12, and this effect was abolished upon treatment with CPP (Fig. 4). To elucidate further the effect of CPP on CXCL12-induced cell invasion, we used the BD BioCoat Matrigel invasion assay system and found that treatment with CPP suppressed CXCL12-induced invasion of HepG2 cells (Fig. 5).

We simulated molecular docking of coumarins with a I $\mathrm{B} \alpha / \mathrm{NF}-$ $\kappa B$ crystal structure (PDB: 1IKN). For details of the docking routine, please see Supplementary information. Docked coumarins were observed at the interface of p65 (a subunit of NF- $\kappa \mathrm{B}$ ) and $\mathrm{I} \kappa \mathrm{B} \alpha$ (an inhibitory protein of $\mathrm{NF}-\kappa \mathrm{B}$ ), thereby replacing the $\mathrm{p} 50$ sub-unit in the complex (Fig. 6). A hydrophobic cavity formed by His-245 and Arg-246 of p65 and Tyr-248, Tyr-251, and Tyr-289 is targeted. These regions are partially occupied by Val-251 and Leu-269 in the native complex with p50. Lead compound CPP scored best amongst the 26 docked coumarin compounds. In addition to the hydrophobic interactions predicted for most members of the series, this compound extends further into a more polar region. Thereby, we observe hydrogen bonding between CPP's ester moiety and the side-chain of Tyr-251 and hydrogen bonding to the backbone of Ser-288. The coumarin scaffold is tightly bound via Van der Waals interactions and a hydrogen bond to the backbone of Asp-290.

In conclusion, the over activation of NF- $\kappa \mathrm{B}$ in cancer cells provides a unique target for the design of therapeutic agents. NF- $\kappa \mathrm{B}$ is reported to regulate more than 200 genes connected to cell proliferation (cyclin D1 and C-Myc), survival (survivin), anti-apoptosis (Bcl-2), inflammation (COX2), angiogenesis (VEGF), and metastasis (MMPs).$^{8,27}$ Of these gene products, cyclin D1 and C-Myc are crucial cell cycle regulators involved in proliferation, Bcl-2 and survivin are anti-apoptotic proteins, and survivin is reported to associate with drug resistance in breast cancer. ${ }^{28}$ MMPs are a large class of proteins with more than 20 types, and generally noted as extracellular matrix degrading proteases. Many MMPs contribute to the dislodging and migration of tumor cells, and have been implicated in cancer progression. MMP1, MMP3 and MMP12 are the major NF- $\mathrm{BB}$ regulated matrix metalloproteinase genes. The role of MMP12 in cancer development is not articulate, but researchers correlated the elevated levels of MMP12 with poor prognosis of HCC in the past. ${ }^{29}$ Blockade of NF- $\kappa$ B DNA binding can result in suppression of its gene products. Therefore, we investigated whether the NF- $\kappa \mathrm{B}$ signaling in HepG2 cells can be modulated by newly synthesized coumarins. Among the new series of coumarins, CPP proved to be a potent anti-proliferative agent against all the three HCC cells and did not show toxicity towards non-diseased cells. Further evaluation showed that CPP decrease the DNA binding ability of NF- $\kappa B$, indicating the possible reduction in corresponding gene products. This reduction was apparent during evaluation of the levels of NF- $\kappa B$ regulated gene products such as cyclin D1, Bcl-2, Survivin, C-Myc, and MMP12. PARP is an integral part of cellular DNA repair machinery and a target of caspase- 3 and caspase-7. ${ }^{30}$ Our western blotting results clearly suggest the cleavage of PARP from a $116 \mathrm{kDA}$ protein into an $89 \mathrm{kDA}$ fragment, evidencing that CPP induces apoptosis. We also found that CPP exert anticancer effects by inhibiting migration and invasion of HCC cells. Thus, our results strongly demonstrate that the anti-oncogenic property of CPP in HCC is mediated through suppression of NF- $\kappa B$ signaling pathway.

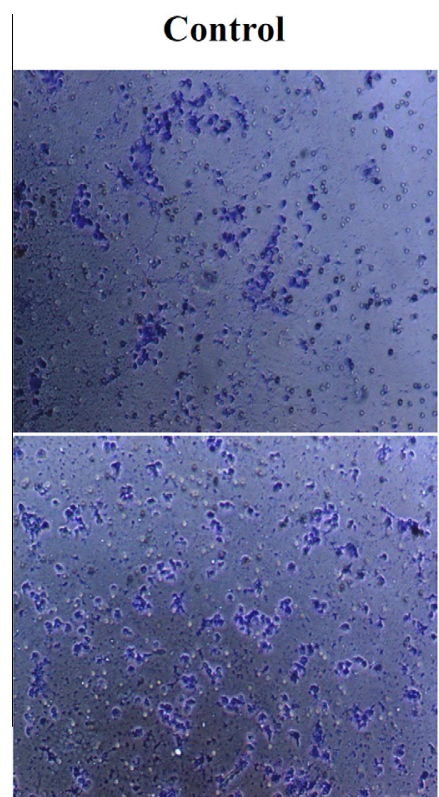

CXCL12
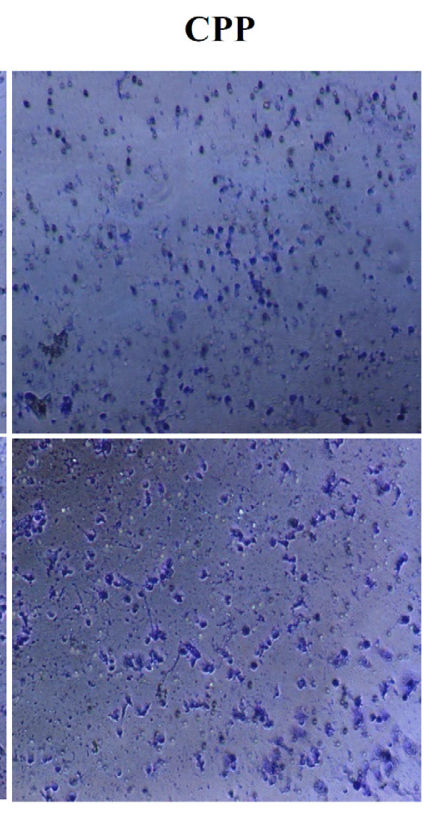

CXCL12 + CPP

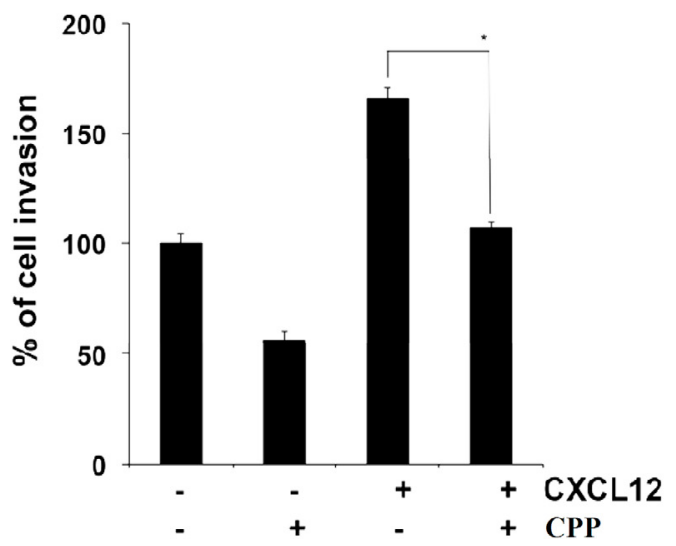

Figure 5. CPP suppresses invasion in HCC cells. A, HepG2 $\left(1 \times 10^{5}\right.$ cells $)$ were seeded in the top-chamber of the BD Matrigel invasion chamber. After preincubation with or without $50 \mu \mathrm{M} \mathrm{CPP}$ for $8 \mathrm{~h}$, transwell chambers were then placed into the wells of a 24-well plate into which we added either the basal medium only or basal medium containing $100 \mathrm{ng} / \mathrm{mL}$ CXCL12 in a predetermined arrangement. After incubation, for $24 \mathrm{~h}$ cell invasion was analyzed and columns represent mean percentage of invaded cells. 
A

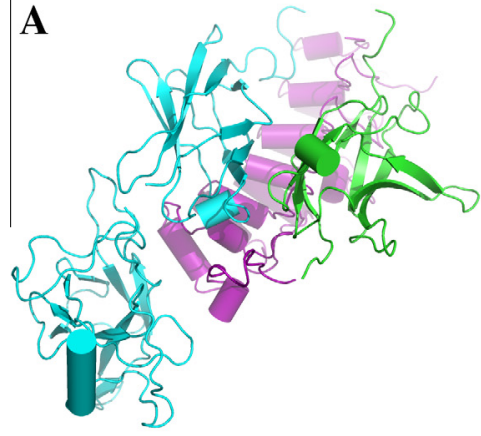

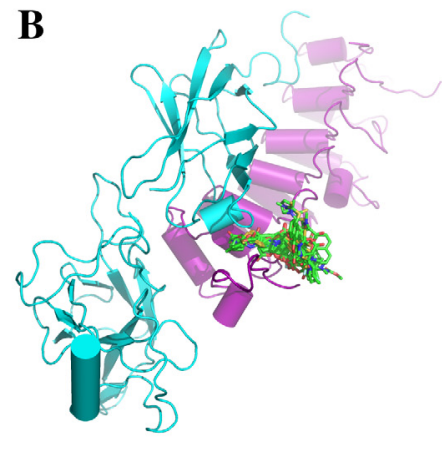

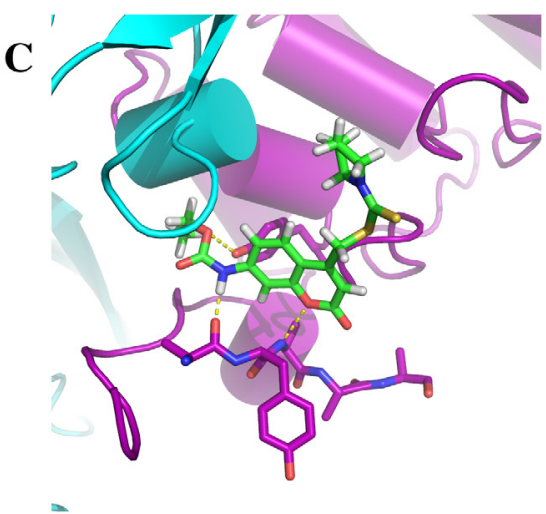

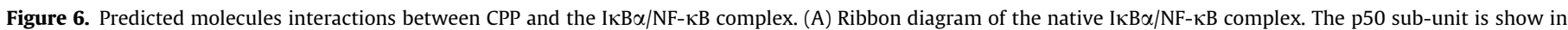

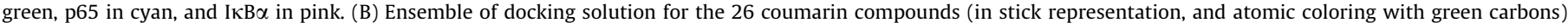

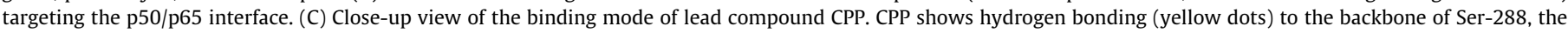
backbone of Asp-290, and the side-chain of Tyr-251.

\section{Acknowledgments}

This research was supported by University Grants Commission (41-257-2012-SR), Vision Group Science and Technology, Department of Science and Technology (NO. SR/FT/LS-142/2012) to Basappa and DST Indo-Korea project [INT/indo-korea/122/2011-12] to K.S.R. This work was supported by grants from NUS Academic Research Fund [Grants R-184-000-207-112] to G.S. Basappa thanks Karnataka University, INDIA for PAVATE fellowship. C.D.M. thanks DST for INSPIRE fellowship. S.P. thanks the Netherlands Organisation for Scientific Research (NWO, grant number NWO-017.009065) and the Prins Bernhard Cultuurfonds for funding.

\section{Supplementary data}

Supplementary data (detailed experimental procedures for the synthesis and the pharmacological investigations) associated with this article can be found, in the online version, at http://dx.doi.org/ 10.1016/j.bmcl.2014.12.065.

\section{References and notes}

1. Rajendran, P.; Ong, T. H.; Chen, L.; Li, F.; Shanmugam, M. K.; Vali, S.; Abbasi, T.; Kapoor, S.; Sharma, A.; Kumar, A. P.; Hui, K. M.; Sethi, G. Clin. Cancer Res. 2011 $17,1425$.

2. Sun, B.; Karin, M. J. Hepatol. 2012, 56, 704.

3. Rampone, B.; Schiavone, B.; Martino, A.; Viviano, C.; Confuorto, G. World J Gastroenterol. 2009, 15, 3210.

4. Yau, T.; Chan, P.; Epstein, R.; Poon, R. T. Liver Int. 2009, 29, 10.

5. Li, F.; Sethi, G. Biochim. Biophys. Acta 2010, 1805, 167.

6. Shen, H. M.; Tergaonkar, V. Apoptosis 2009, 14, 348.

7. Vallabhapurapu, S.; Karin, M. Annu. Rev. Immunol. 2009, 27, 693.

8. Aggarwal, B. B. Cancer Cell 2004, 6, 203.

9. Ivanov, V. N.; Ghandhi, S. A.; Zhou, H.; Huang, S. X.; Chai, Y.; Amundson, S. A.; Hei, T. K. Exp. Cell Res, 2011, 317, 1548.

10. Lacy, A.; O’Kennedy, R. Curr. Pharm. Des. 2004, 10, 3797.
11. Fylaktakidou, K. C · Hadjipavlou-Litina, D. J· Litinas, K. E · Nicolaides, D. N. Curr. Pharm. Des. 2004, 10, 3813.

12. Kontogiorgis, C.; Hadjipavlou-Litina, D. J. Enzyme Inhib. Med. Chem. 2003, 18, 63.

13. Sukhorukov, A. Y.; Nirvanappa, A. C.; Swamy, J.; Ioffe, S. L.; Nanjunda Swamy, S.; Basappa; Rangappa, K. S. Bioorg. Med. Chem. Lett. 2014, 24, 3618.

14. Sugahara, K.; Thimmaiah, K. N.; Bid, H. K.; Houghton, P. J.; Rangappa, K. S. PloS ONE 2012, 7, e39444.

15. Basappa, K.; Murugan, S.; Kavitha, C. V.; Purushothaman, A.; Nevin, K. G.; Sugahara, K.; Rangappa, K. S. Cancer Lett. 2010, 297, 231.

16. Rangappa, K. S.; Basappa J. Phys. Org. Chem. 2005, 18, 773.

17. Sebastian, A.; Siddappa, A. B.; Mohan, C. D.; Nagabhushana, G. T.; Shubha, P. B.; Rangappa, K. S.; Basappa, S.; Chandrappa, G. T. RSC Adv. 2014, 4, 52181.

18. Kumar, C. A.; Swamy, S. N.; Gaonkar, S. L.; Basappa; Salimath, B. P.; Rangappa, K. S. Med. Chem. 2007, 3, 269.

19. Mantelingu, K.; Sadashiva, M.; Rangappa, K. Indian J. Chem., Sect. B 2004, 43, 1954.

20. Name Reactions; Li, J., Ed.; Springer International Publishing, 2014; p 466.

21. Keerthy, H. K.; Garg, M.; Mohan, C. D.; Madan, V.; Kanojia, D.; Shobith, R.; Nanjundaswamy, S.; Mason, D. J.; Bender, A.; Basappa; Rangappa, K. S.; Koeffler, H. P. PloS ONE 2014, 9, e107118.

22. Mohan, C. D.; Bharathkumar, H.; Bulusu, K. C.; Pandey, V.; Rangappa, S.; Fuchs, J. E.; Shanmugam, M. K.; Dai, X.; Li, F.; Deivasigamani, A.; Hui, K. M.; Kumar, A. P.; Lobie, P. E.; Bender, A.; Basappa; Sethi, G.; Rangappa, K. S. J. Biol. Chem. 2014

23. Yamamoto, K.; Arakawa, T.; Ueda, N.; Yamamoto, S. J. Biol. Chem. 1995, 270, 31315.

24. Tamatani, M.; Che, Y. H.; Matsuzaki, H.; Ogawa, S.; Okado, H.; Miyake, S.; Mizuno, T.; Tohyama, M. J. Biol. Chem. 1999, 274, 8531.

25. Hanahan, D.; Weinberg, R. A. Cell 2011, 144, 646.

26. Bharathkumar, H.; Paricharak, S.; Dinesh, K.; Siveen, K. S.; Fuchs, J. E.; Rangappa, S.; Mohan, C.; Mohandas, N.; Kumar, A. P.; Sethi, G. RSC Adv. 2014, 4, 45143 .

27. Olivier, S.; Robe, P.; Bours, V. Biochem. Pharmacol. 2006, 72, 1054.

28. Gritsko, T.; Williams, A.; Turkson, J.; Kaneko, S.; Bowman, T.; Huang, M.; Nam, S.; Eweis, I.; Diaz, N.; Sullivan, D.; Yoder, S.; Enkemann, S.; Eschrich, S.; Lee, J H.; Beam, C. A.; Cheng, J.; Minton, S.; Muro-Cacho, C. A.; Jove, R. Clin. Cancer Res. 2006, 12, 11.

29. Ng, K. T.; Qi, X.; Kong, K. L.; Cheung, B. Y.; Lo, C. M.; Poon, R. T.; Fan, S. T.; Man, K. Eur. J. Cancer. 2011, 47, 2299.

30. Keerthy, H. K.; Mohan, C. D.; Siveen, K. S.; Fuchs, J. E.; Rangappa, S.; Sundaram, M. S.; Li, F.; Girish, K. S.; Sethi, G.; Basappa, B. J. Biol. Chem. 2014 jbc.M114.593855. 